\title{
The Dynamics of Ammonia Metabolism in Man
}

\author{
EFFECTS OF LIVER DISEASE AND HYPERAMMONEMIA
}

\author{
Alan H. Lockwood, Joseph M. McDonald, Robert E. Reiman, Alan S. Gelbard, \\ John S. Laughlin, Thomas E. Duffy, and Fred Plum, Departments of \\ Neurology and Biochemistry, Cornell University Medical College, and \\ Biophysics Laboratory, Memorial Sloan-Kettering Cancer Center, \\ New York 10021
}

A в S T RACT The cyclotron-produced radionuclide, ${ }^{13} \mathrm{~N}$, was used to label ammonia and to study its metabolism in a group of 5 normal subjects and 17 patients with liver disease, including 5 with portacaval shunts and 11 with encephalopathy. Arterial ammonia levels were 52-264 $\mu \mathrm{M}$. The rate of ammonia clearance from the vascular compartment (metabolism) was a linear function of its arterial concentration: $\mu \mathrm{mol} / \mathrm{min}=4.71$ $\left[\mathrm{NH}_{3}\right]_{\mathrm{a}}+3.76, r=+0.85, P<0.005$. Quantitative body scans showed that $7.4 \pm 0.3 \%$ of the isotope was metabolized by the brain. The brain ammonia utilization rate, calculated from brain and blood activities, was a function of the arterial ammonia concentration: $\mu \mathrm{mol} /$ min per whole brain $=0.375\left[\mathrm{NH}_{3}\right]_{\mathrm{a}}-3.6, r=+0.93$, $P<0.005$. Assuming that cerebral blood flow and brain weights were normal, $47 \pm 3 \%$ of the ammonia was extracted from arterial blood during a single pass through the normal brains. Ammonia uptake was greatest in gray matter. The ammonia utilization reaction(s) appears to take place in a compartment, perhaps in astrocytes, that includes $<20 \%$ of all brain ammonia. In the 11 nonencephalopathic subjects the $\left[\mathrm{NH}_{3}\right]_{\mathrm{a}}$ was $100 \pm 8$ $\mu \mathrm{M}$ and the brain ammonia utilization rate was $32 \pm 3$ $\mu \mathrm{mol} / \mathrm{min}$ per whole brain; in the 11 encephalopathic subjects these were respectively elevated to $149 \pm 18$ $\mu \mathrm{M}(P<0.01)$, and $53 \pm 7 \mu \mathrm{mol} / \mathrm{min}$ per whole brain $(P<0.01)$. In normal subjects, $\cong 50 \%$ of the arterial ammonia was metabolized by skeletal muscle. In patients with portal-systemic shunting, muscle may become the most important organ for ammonia detoxification. Muscle atrophy may thereby contribute to the de-

Dr. Lockwood held National Institutes of Health Research Fellowship NS-02149 and Dr. Duffy is an Established Investigator of the American Heart Association. Dr. Lockwood's present address is Department of Neurology, University of Miami School of Medicine, Miami, Fla.

Received for publication 4 August 1977 and in revised form 26 October 1978. velopment of hyperammonemic encephalopathy with an associated increase in the brain ammonia utilization rate.

\section{INTRODUCTION}

Ammonia, ${ }^{1}$ one of the principal products of nitrogen metabolism, is normally converted to urea, in the liver, by a series of enzymatic reactions. Liver disease and congenital or acquired defects in the urea cycle may cause elevations in the blood ammonia concentration (1-4). Ammonia is highly neurotoxic and, along with other factors, undoubtedly contributes to the development of encephalopathy and coma that is often a terminal event in patients with severe liver disease $(1,2)$.

Because the concentration of ammonia in hepatic portal vein blood is normally 5-10 times greater than in mixed venous blood, the gastrointestinal tract is presumed to be the site of most ammonia production (5). Although much of the ammonia in the hepatic portal system is metabolized by the liver, little direct information is available concerning the metabolism of ammonia in the systemic circulatory system (5-10). Accordingly, we have studied the metabolic fate of intravenously injected ${ }^{13} \mathrm{~N}$-ammonia, in 5 normal subjects and 17 patients with liver disease. ${ }^{13} \mathrm{~N}$ is a positronemitting isotope $\left(t_{1 / 2}=10.0 \mathrm{~min}\right)$ that gives rise to annihilation gamma ray photons with an energy of 511 Kiloelectron volts; its rate of clearance from blood (metabolism), rate of utilization by the brain, and equilibrium distribution in the body can be studied with appropriate external imaging and counting equipment with little invasiveness.

\footnotetext{
1 Throughout this report the term "ammonia" will be used to refer to the sum of the ammonia gas and ammonium ion content of an aqueous solution at a given $\mathrm{pH}$. The gas or the ion will be referred to specifically.
} 


\section{METHODS}

Subject selection and evaluation. All procedures described in this report and the methods for obtaining consent from the patients and their families were reviewed and approved by the New York Hospital-Cornell Medical Center Human Rights in Research Committee and by the Memorial Sloan-Kettering Cancer Center Clinical Investigation Committee and Committee on Radioactive Materials, New York.

On the basis of a history, review of clinical records, and physical and neurological examinations, all subjects were placed in one of four groups: $(a)$ normal controls were free of liver and central nervous system disease; $(b)$ subjects with mild liver disease had hepatomegaly or abnormal liver function tests, but did not have evidence of cirrhosis and had never required hospitalization for the diagnosis or treatment of liver disease; $(c)$ subjects with severe liver disease had cirrhosis of the liver, portal hypertension, and had required hospitalization for the treatment of hepatic encephalopathy, ascites, or gastrointestinal hemorrhage because of ruptured esophageal varices; $(d)$ subjects with malignant neoplasms had metastases in the liver, without evidence of metastases in the central nervous system. The degree of encephalopathy was graded in all subjects with liver disease using the following criteria: 0 , no evidence of encephalopathy; 1 , mild encephalopathy, with slight confusion, lethargy, and slurred speech; 2, moderate encephalopathy, with lethargy, disorientation, asterixis, hyper-reflexia, and hyperventilation; 3, severe encephalopathy, with no meaningful response to verbal stimuli but appropriate responses to noxious stimuli. No deeply unresponsive patients were included in the study.

Subjects were studied when they were available and no dietary restrictions were imposed before the investigation. Several subjects with liver disease were on low protein diets and were being treated with oral neomycin. Those recovering from an episode of hepatic encephalopathy were usually receiving intravenous fluids, oral antibiotics, and enemas.

Isotope production and assay methods. ${ }^{13} \mathrm{~N}-\mathrm{Ammonia}$ was produced by the ${ }^{16} \mathrm{O}(\mathrm{p}, \alpha)^{13} \mathrm{~N}$ nuclear reaction, using a water target and a proton beam from a cyclotron, as described by Gelbard et al. (11). The ${ }^{13} \mathrm{~N}$-ammonia, produced by this method, is essentially radiochemically pure and carrier-free. ${ }^{2}$ The isotope was collected in phosphate-buffered, $0.9 \%$ sodium chloride, $\mathrm{pH} 7.2$, and passed through a Millipore filter (Millipore Corp., Bedford, Mass.). A portion of the dose was diluted to $10.0 \mathrm{ml}$ with $0.9 \%$ sodium chloride, and the activity was measured, using constant geometry, in an ion chamber. The dose was injected intravenously when it decayed to $10.0 \mathrm{mCi}$ or less.

The arterial ammonia concentration was measured in two to three blood samples that were collected at intervals during $1 \mathrm{~h}$ required to complete the study. Blood samples were immediately deproteinized with $1.2 \mathrm{M}$ perchloric acid. The supernatant solution was neutralized with $2.0 \mathrm{M} \mathrm{KHCO}_{3}$, stored at $-80^{\circ} \mathrm{C}$, and assayed for the ammonia content using the enzymatic fluorometric method of Folbergrová et al. (12). The mean arterial ammonia concentration was used in all calculations for each study.

The total blood volume was measured in 14 subjects, using ${ }^{125}$ I-radioiodinated serum albumin, by the New York Hospital Nuclear Medicine Laboratory, New York.

General experimental procedures. With the subject in the supine position on a scanner table, and after the adequacy of

\footnotetext{
${ }^{2}$ Assays of the injected sample of ${ }^{13} \mathrm{~N}$-ammonia showed that they each contained $\cong 1 \mu \mathrm{mol}$ ammonia $/ 10 \mathrm{ml}$ and one part of ${ }^{18} \mathrm{~F}$ per $10^{5}$ parts of ${ }^{13} \mathrm{~N}$, measured at the end of the target bombardment.
}

the ulnar arterial blood supply to the hand had been established with an Allen test, a 20-gauge, nontapered Teflon Longdwell catheter (Becton, Dickinson \& Co., Rutherford, N. J.) was percutaneously inserted into the left radial artery, using a local anesthetic and an aseptic technique. The catheter was irrigated frequently with $0.9 \%$ sodium chloride containing $100 \mathrm{U}$. S. Pharmacopeia U of heparin $/ \mathrm{ml}$. A scalp vein needle was inserted into a large peripheral vein in the right arm and was used for the ${ }^{13} \mathrm{~N}$-ammonia injection.

At the beginning of the study, the subject's head was placed under an Anger-type gamma camera (13), in the left lateral position. The gamma camera was activated at the same instant that the isotope $(10.0 \mathrm{mCi})$ was injected into the peripheral vein. Serial arterial blood samples $(0.2 \mathrm{~g})$ were collected from the radial artery catheter beginning $\cong 0.20 \mathrm{~min}$ after the injection. 25 blood samples were collected in tared tubes in the first $2.5 \mathrm{~min}$ after the injection; additional samples $(0.5-1.0 \mathrm{~g})$ were collected $3,5,7,10,15$, and $20 \mathrm{~min}$ after the injection. All sample collections were timed to the nearest $0.01 \mathrm{~min}$. Blood activity was measured with a Packard gamma spectrometer (Packard Instrument Co., Inc., Downers Grove, Ill.) and corrected for isotope decay to the time of injection. The sample weight was determined and blood activity was calculated as counts per time per volume, using the nomogram of Van Slyke et al. (14) to convert blood weight to volume.

Head imaging was completed 10 min after the injection of the isotope, and the subject was moved to the Sloan Kettering Institute High Energy Gamma (HEG) ${ }^{3}$ rectilinear scanner. A body scan covering the area from the head to the lower thigh was obtained, using appropriate collimators and a $2.0 \times 2.0$ $\mathrm{cm}$ scan element size $(15,16)$. The body scan was started 15-20 min after the injection of the isotope and required 30-40 min to complete, depending on the size of the subject.

Head and body images were generated on a storage oscilloscope, using increasing dot densities (16 levels were available) to show increasing levels of ${ }^{13} \mathrm{~N}$ activity. When more than 16 levels of activity were required for an image, the dot density was "recycled" and the 17th level of activity had the same dot density as the first.

Calculation of ammonia clearance rate. In the steady state, the rate of removal of a compound from the vascular compartment, or clearance, can be calculated by dividing the tracer dose by the integral of the specific activity curve for the tracer (17). The specific activity of arterial ${ }^{13} \mathrm{~N}$-ammonia was calculated by subtracting the radioactivity due to metabolized ${ }^{13} \mathrm{~N}$-ammonia from the measurement of the total radioactivity of arterial blood. Nonammonia activity was defined as ${ }^{13} \mathrm{~N}$ activity that was not volatile in a strong potassium carbonate solution. Heparinized arterial blood samples $(1.0 \mathrm{ml})$ were collected $3,5,7$, and $10 \mathrm{~min}$ after the injection of the isotope from subjects Nos. $5,7,8,21$, and 22B, and added to an equal volume of a saturated aqueous potassium carbonate solution in the outer ring of a Conway diffusion chamber (Fisher Scientific Co., Pittsburgh, Pa.). After $20 \mathrm{~min}$ of constant agitation at room temperature, the radioactivity of $1.0 \mathrm{ml}$ of the alkalinized blood solution was measured. Under these conditions, $85 \%$ of the ${ }^{13} \mathrm{~N}$-ammonia added to heparinized blood in vitro was volatilized. This measurement was repeated and used as the control for each volatilization yield.

The nonvolatile ${ }^{13} \mathrm{~N}$ activity in blood was assumed to be zero when the intravenously injected ${ }^{13} \mathrm{~N}$ activity was first detectable in arterial blood. When metabolized ${ }^{13} \mathrm{~N}$ activity was

${ }^{3}$ Abbreviations used in this paper: BAUR, brain ammonia utilization rate; HEG, high energy gamma. 
expressed as a percent of the total activity, a linear relationship was found up to the 10th $\mathrm{min}$ after the injection: percent metabolized $=10.13$ (minutes after injection) -0.88 , $r=+0.85, P<0.005$. The integral of the metabolized ${ }^{13} \mathrm{~N}$ activity accounted for $21-24 \%$ of the value of the integral of the total ${ }^{13} \mathrm{~N}$ activity between 0 and $10 \mathrm{~min}$ after the injection of the isotope. For the investigations in which the metabolized ${ }^{13} \mathrm{~N}$ activity was not measured directly, this linear relationship was evaluated at $3,5,7$, and $10 \mathrm{~min}$, integrated from $0-10$ min, and subtracted from the integral of the total arterial ${ }^{13} \mathrm{~N}$ activity. Because the specific activity of ${ }^{13} \mathrm{~N}$-ammonia approached zero $10 \mathrm{~min}$ after the injection of the isotope (see Fig. $1)$, the integral of the specific activity of ammonia from 0 to $10 \mathrm{~min}$ is a valid approximation of the value of the integral of the total specific activity curve. Accordingly, this time frame was used in all clearance measurements and calculations.

Measurement of organ-specific ${ }^{13} \mathrm{~N}$ content. The data obtained from the body scans were used to calculate organspecific ${ }^{13} \mathrm{~N}$ contents. Both absolute and relative quantitation methods were employed. In the absolute quantitation studies, the summed count rate in the brain was compared to the summed count rate of a human skull filled with aqueous ${ }^{18} \mathrm{~F}$. The validity of this approach has been proven in the case of splenic sequestration of ${ }^{51} \mathrm{Cr}(15,16)$. In the relative quantitation studies, the summed count rate in the organ of interest is expressed as a percent of the summed count rate in the whole scan.

The collimators used in this study were designed to have a uniform sensitivity and resolution, regardless of the position of a source between the detectors. To evaluate the uniformity of the system, the sensitivity (integral of the linespread function) and the resolution (full width at half maximum) were measured as the detector pair was moved

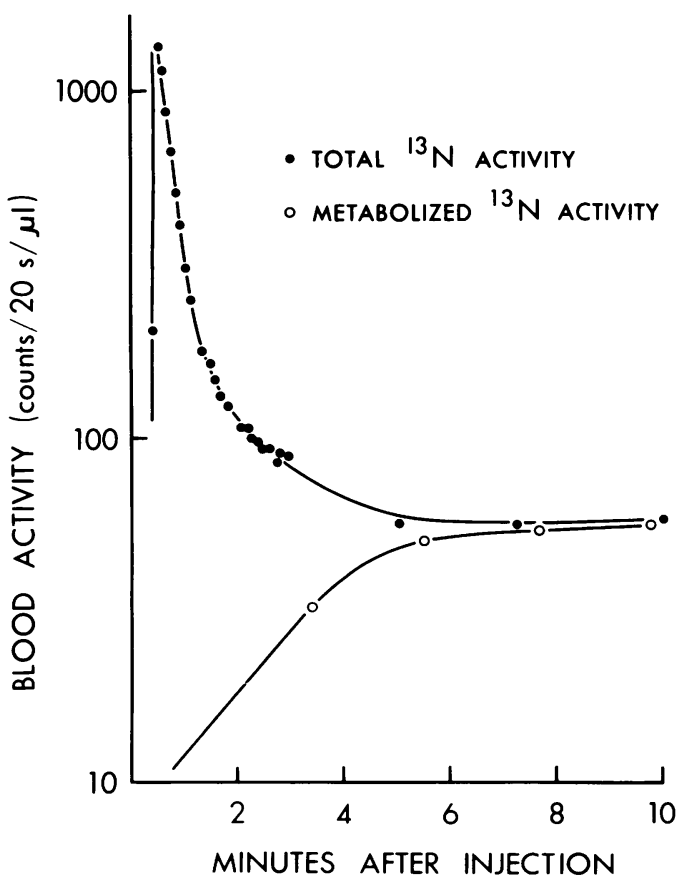

FIGURE 1 Arterial ${ }^{13} \mathrm{~N}$ activity. A bolus of $7.84 \mathrm{mCi}$ of ${ }^{13} \mathrm{~N}$ ammonia was injected intravenously at time 0 (subject 8 ). The curves were integrated, and metabolized activity was subtracted from total activity to give the integral of the specific activity of arterial ammonia used in clearance calculations. across a line source filled with ${ }^{18} \mathrm{~F}$. The position of the source was varied within a $16-\mathrm{cm}$ block of tissue-equivalent material (Mix D [18]). Although the resolution was best when the source was closest to either detector, the difference between the maximum and minimum values (2.1 vs. $1.8 \mathrm{~cm}$ ) was $14 \%$. There were similar variations in the sensitivity. This degree of variation is comparable to that reported by Kuhl et al. (19) for head images obtained with the Mark IV tomographic system.

The method of absolute quantitation was used to measure the total brain activity at equilibrium in 5 subjects (Nos. 5, 7, $8,14$, and $22 \mathrm{~A})$. For these measurements the head only was scanned. Care was taken to place the skull phantom and the test subjects in exactly the same position to avoid errors resulting from differences in geometry. With the exception of the absent skin and muscle that surround the brain, the photon attenuation by the phantom should be very similar to that in a subject. This factor and the constancy of geometric variables that affect the depth-dependent variations in the sensitivity and resolution, should permit a measurement of the total amount of ${ }^{13} \mathrm{~N}$ in the brain with an error $\cong 10 \%$.

A method of relative quantitation was used to calculate the brain activity for each of the same five subjects. The summed count rate over the brain was divided by the summed count rate in the complete scan. This quotient should equal the fraction of the dose in the brain. The relative constancy of brain size, skull configuration, and density should have produced only small variations in attenuation of the highenergy $\gamma$-ray photons in the head. Morphological differences between subjects (short vs. tall, cachexia vs. massive ascites) could cause much larger variations in photon attenuation and, secondarily, errors in the determination of the summed count rate in the complete scan. To determine the importance of this problem, the summed count rate in the scan was plotted as a function of the injected ${ }^{13} \mathrm{~N}$-ammonia activity, decaycorrected to the time of the scan. There was a linear relationship between these two variables with a high correlation coefficient, $r=+0.98$. The high degree of correlation implied that the total summed count rate in the scan was a valid measure of the total amount of ${ }^{13} \mathrm{~N}$ in each subject. However, it was recognized that the ratio of the brain region count rate and the total body count rate would not necessarily equal the fraction of the injected dose actually present in the brain. An independent measure of brain ${ }^{13} \mathrm{~N}$ content that does not depend on external scanning is not available; however, the absolute quantitation method outlined previously is valid on theoretical grounds and was used to help determine the relationship between the relative activity and the true activity. When the results of the relative and absolute methods were compared for these five subjects via a paired $t$ test, there was no significant difference between the methods. Accordingly, the method of relative quantitation was used for all organ activity calculations.

The favorable conditions that permitted the application of the relative method for the determination of brain ${ }^{13} \mathrm{~N}$ content do not hold for axial body organs, because of the greater variability in the positioning of these organs and in the amount of attenuating tissue. Phantom studies indicated that the errors in the measurement of liver and urinary bladder activity are $\cong 20 \%$.

\section{RESULTS}

A summary of the pertinent clinical data for each subject appears in Table I. Liver disease in this population was most commonly the result of alcoholism, but subjects with cryptogenic and posthepatitic cirrhosis, Wil- 
TABLE I

The Subject Population

\begin{tabular}{|c|c|c|c|c|c|c|c|}
\hline & $\begin{array}{l}\text { Subject } \\
\text { No. }\end{array}$ & Age & Sex & Clinical diagnosis & $\begin{array}{c}\text { Arterial } \\
\text { ammonia }\end{array}$ & Physical findings & $\begin{array}{l}\text { Encephalopathy } \\
\text { grade }\end{array}$ \\
\hline & & $y r$ & & & umollliter & & \\
\hline \multirow[t]{5}{*}{$\begin{array}{l}\text { Normal } \\
\text { controls }\end{array}$} & 1 & 51 & Male & Normal & 103 & & \\
\hline & 2 & 32 & Male & Normal & 110 & & \\
\hline & 3 & 35 & Male & Normal & 113 & & \\
\hline & 4 & 31 & Female & Normal & 89 & & \\
\hline & 5 & 30 & Male & Normal & 73 & & \\
\hline \multirow[t]{3}{*}{$\begin{array}{l}\text { Mild liver } \\
\text { disease }\end{array}$} & 6 & 51 & Male & $\begin{array}{l}\text { Hepatomegaly from } \\
\text { alcohol ingestion }\end{array}$ & 136 & Hepatomegaly & 0 \\
\hline & 7 & 18 & Male & Wilson's Disease & 81 & $\begin{array}{l}\text { Dysarthria, sialorrhea, } \\
\text { cog-wheel rigidity, } \\
\text { Kayser-Fleischer ring }\end{array}$ & 0 \\
\hline & 8 & 32 & Female & $\begin{array}{l}\text { Hepatomegaly, unknown } \\
\text { cause }\end{array}$ & 52 & Hepatomegaly & 0 \\
\hline \multirow[t]{2}{*}{$\begin{array}{l}\text { Metastatic } \\
\text { cancer }\end{array}$} & 9 & 39 & Male* & $\begin{array}{l}\text { Adenocarcinoma of colon, } \\
\text { metastatic to liver, } \\
\text { lungs }\end{array}$ & 97 & $\begin{array}{l}\text { Liver edge at pelvic brim, } \\
\text { Massive ascites }\end{array}$ & 1 \\
\hline & 10 & 64 & Female & $\begin{array}{l}\text { Adenocarcinoma of colon, } \\
\text { metastatic to liver }\end{array}$ & 71 & Hepatomegaly & 0 \\
\hline \multirow[t]{7}{*}{$\begin{array}{l}\text { Severe liver } \\
\text { disease }\end{array}$} & 11 & 48 & Male* & $\begin{array}{l}\text { Cryptogenic cirrhosis, } \\
\text { portacaval shunt (1971), } \\
\text { chronic encephalopathy }\end{array}$ & 136 & $\begin{array}{l}\text { Cachexia, hepatomegaly, } \\
\text { + Babinski }\end{array}$ & $1-2$ \\
\hline & 12 & 53 & Male & $\begin{array}{l}\text { Post hepatic cirrhosis, } \\
\text { portacaval shunt (1975), } \\
\text { portal hypertension }\end{array}$ & 140 & $\begin{array}{l}\text { Hepatomegaly, Ascites, } \\
\text { muscle wasting }\end{array}$ & 0 \\
\hline & 13 & 39 & Male & $\begin{array}{l}\text { Laennec's cirrhosis, } \\
\text { portacaval shunt ( } 1 \mathrm{wk})\end{array}$ & 148 & $\begin{array}{l}\text { Resolving hepatic coma, } \\
\text { hepatomegaly, spider } \\
\text { angiomata, ascites }\end{array}$ & 1 \\
\hline & 14 & 68 & Female* & $\begin{array}{l}\text { Cryptogenic cirrhosis, } \\
\text { portal hypertension, } \\
\text { esophageal varices, } \\
\text { chronic encephalopathy }\end{array}$ & 181 & $\begin{array}{l}\text { Shrunken liver, massive } \\
\text { ascites, pedal edema }\end{array}$ & 2 \\
\hline & 15 & 30 & Female & $\begin{array}{l}\text { Intrahepatic cholestasis, } \\
\text { cirrhosis, portacaval } \\
\text { shunt (1970), recurrent } \\
\text { encephalopathy }\end{array}$ & 146 & $\begin{array}{l}\text { Marked jaundice, normal- } \\
\text { sized liver, muscle } \\
\text { atrophy }\end{array}$ & 1 \\
\hline & 16 & 73 & Male & $\begin{array}{l}\text { Laennec's cirrhosis, } \\
\text { portal hypertension, } \\
\text { resolving encepha- } \\
\text { lopathy }\end{array}$ & 62 & $\begin{array}{l}\text { Spider angiomata, dilated } \\
\text { abdominal veins, } \\
\text { hepatomegaly, } \\
\text { + Babinski }\end{array}$ & 2 \\
\hline & 17 & 59 & Male & $\begin{array}{l}\text { Alcoholic hepatitis, } \\
\text { thrombocytopenia }\end{array}$ & 120 & $\begin{array}{l}\text { Gynecomastia, } \\
\text { hepatomegaly }\end{array}$ & 0 \\
\hline
\end{tabular}




\begin{tabular}{|c|c|c|c|c|c|c|}
\hline $\begin{array}{l}\text { Subject } \\
\text { No. }\end{array}$ & Age & Sex & Clinical diagnosis & $\begin{array}{c}\text { Arterial } \\
\text { ammonia }\end{array}$ & Physical findings & $\begin{array}{c}\text { Encephalopathy } \\
\text { grade }\end{array}$ \\
\hline & $y r$ & & & $\mu$ molliter & & \\
\hline 18 & 41 & Male & $\begin{array}{l}\text { Laennec's cirrhosis, } \\
\text { portacaval shunt (1 mo) } \\
\text { resolving } \\
\text { encephalopathy, } \\
\text { thrombocytopenia }\end{array}$ & 107 & Cachexia & $1-2$ \\
\hline 19 & 55 & Male* & Laennec's cirrhosis & 153 & Hepatomegaly ascites & 2 \\
\hline 20 & 26 & Male & $\begin{array}{l}\text { Alcoholic hepatitis, } \\
\text { possible hepatoma }\end{array}$ & 180 & $\begin{array}{l}\text { Massive, painful, } \\
\text { hepatomegaly, muscle } \\
\text { atrophy }\end{array}$ & $0-1$ \\
\hline $22 \mathrm{~A}$ & 43 & Female* & $\begin{array}{l}\text { Laennec's cirrhosis, } \\
\text { portal hypertension, } \\
\text { severe myelopathy, } \\
\text { hepato-cerebral } \\
\text { degeneration }\end{array}$ & 228 & $\begin{array}{l}\text { Cachexia, spider angi- } \\
\text { omata, alopecia hepato- } \\
\text { megaly, pure cortico- } \\
\text { spinal tract, myelopathy }\end{array}$ & 1 \\
\hline $22 \mathrm{~B}$ & \multicolumn{2}{|c|}{$\begin{array}{l}\text { Same subject } \\
\quad \text { as } 22 \mathrm{~A}\end{array}$} & & 264 & & 3 \\
\hline
\end{tabular}

The pertinent clinical data are shown for the subjects participating in this investigation.

* These subjects have died of their primary disease.

son's disease, and an intrahepatic bile stasis syndrome were also included. At least six subjects are known to have died as a result of their disease and its complications. One patient (No. 15), underwent a successful liver transplantation after the study. Five subjects with severe liver disease had end-to-side portacaval shunts constructed $1 \mathrm{wk}$ to $5 \mathrm{yr}$ before this investigation.

${ }^{13} \mathrm{~N}$-Ammonia clearance from the vascular compartment. After an intravenous bolus injection of ${ }^{13} \mathrm{~N}$ ammonia, the tracer was rapidly cleared from the vascular compartment. Labeled metabolites of ammonia were detectable in arterial blood within 3 min of the injection, and by the 10th min after the injection, all of the ${ }^{13} \mathrm{~N}$ activity in arterial blood was present as an ammonia metabolite (Fig. 1). The ${ }^{13} \mathrm{~N}$ content of arterial blood remained nearly constant between the 10th and 20 th min after the injection. In the 14 subjects where the blood volume was measured, $6.3 \pm 0.3 \%$ of the injected dose was present in the vascular compartment 20 min after the injection. When the ammonia clearance rate was calculated and plotted as a function of the arterial ammonia concentration, a linear relationship was present $(P<0.001)$ in the concentration range encountered in these subjects (Fig. 2). These results indicate that ammonia clearance is a first order process at normal and moderately elevated arterial ammonia concentrations.

${ }^{13} \mathrm{~N}$ Distribution at equilibrium. The measurements of arterial ${ }^{13} \mathrm{~N}$ activity and ${ }^{13} \mathrm{~N}$-ammonia specific activity suggested that an equilibrium distribution of ${ }^{13} \mathrm{~N}$ was achieved by the 20th min after the injection of the isotope. To test this directly, $3 \mathrm{mCi}$ of ${ }^{13} \mathrm{~N}$ ammonia were injected intravenously into a normal

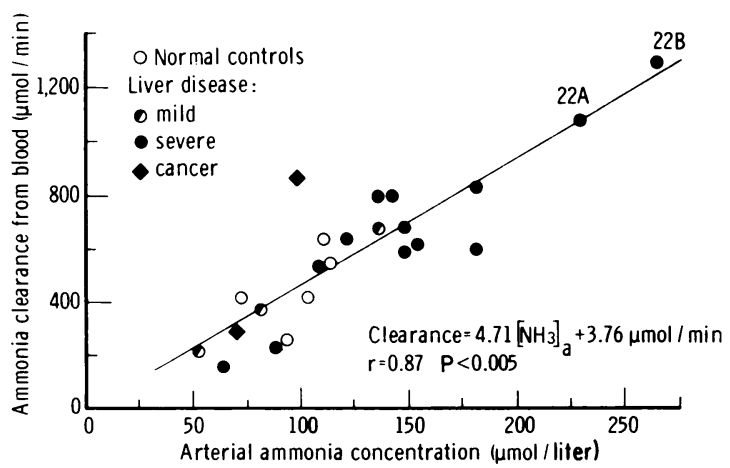

Figure 2 Ammonia clearance from the blood. The arterial ammonia clearance rate was calculated for each subject and is shown as a function of the arterial ammonia concentration. 
subject (No. 3), and the radioactivity of the brain, liver, thigh, and urinary bladder was monitored for the next 50 min with stationary $\mathrm{NaI}(\mathrm{T} 1)$ probes (Fig. 3). The data showed that the distribution of ${ }^{13} \mathrm{~N}$ activity in these regions was reasonably constant $( \pm 5 \%$ for brain) during the period of time required to complete the HEG body scan (i.e., from approximately the 15 th to 50th min after injection).

Technically satisfactory body scans were obtained in 22 of the 23 studies. The brain, liver, and urinary bladder all contained substantial amounts of ${ }^{13} \mathrm{~N}$ activity, and the outline of these organs was seen without difficulty (Fig. 4). Other structures, known to accumulate ${ }^{13} \mathrm{~N}$-ammonia, such as the heart and the kidneys (11), were not well visualized because of methodologic limitations.

The results of the organ ${ }^{13} \mathrm{~N}$ activity distribution calculations are shown in Table II. When all of the subjects were considered as a group, the brain contained $7.4 \pm 0.3 \%$ of the ${ }^{13} \mathrm{~N}$ activity. The brains of the normal subjects contained $6.9 \pm 0.5 \%$, and the brains of the subjects with severe liver disease contained $7.7 \pm 0.3 \%$. The brains of the subjects with severe liver disease and a history of hepatic encephalopathy contained 8.1 $\pm 0.3 \%$ ( $P<0.1$, compared to normals by a two-tailed $t$ test). The trend toward an increase in the brain activity with severe liver disease may be the result of cachexia and a secondary redistribution of ${ }^{13} \mathrm{~N}-$ ammonia.

The bladder and urine of the normal subjects contained $6.4 \pm 0.1 \%$ of the scan activity. This was de-

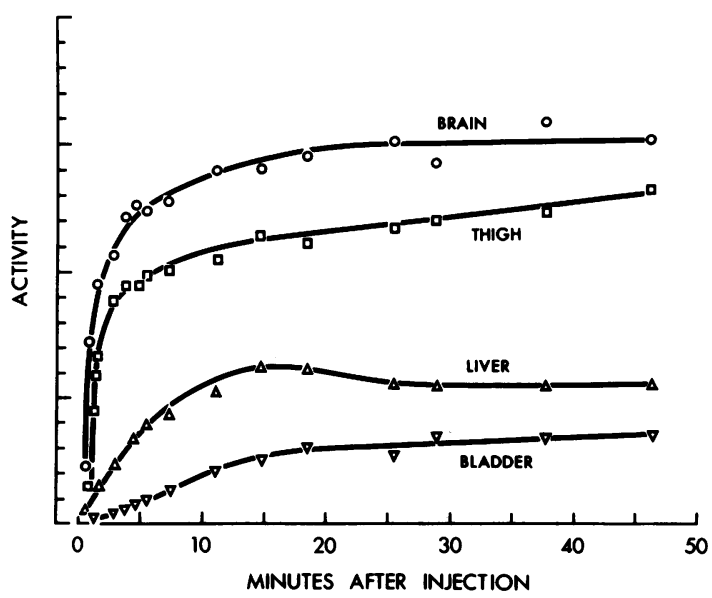

FIGURE 3 Organ activity after an intravenous injection of ${ }^{13} \mathrm{~N}$-ammonia. A bolus of $3.0 \mathrm{mCi}$ of ${ }^{13} \mathrm{~N}$-ammonia was injected into a normal subject. Stationary probes measured radioactivity over the brain, liver, urinary bladder, and thigh. Activity levels are shown in arbitrary units. Organ activity (decay-corrected) was relatively constant during the time interval required to complete the HEG scan, $15-45$ min after the injection. Inter-organ comparisons are not valid because of detector differences.

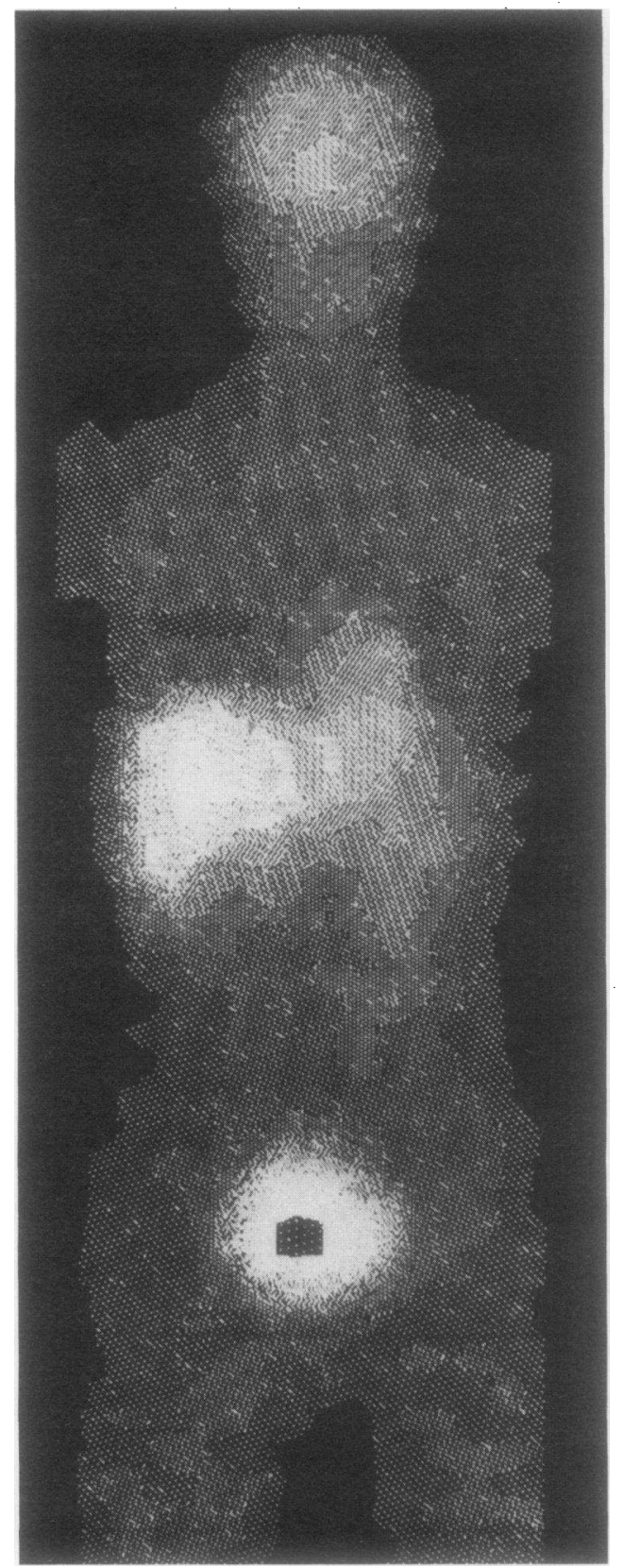

FIGURE $4{ }^{13} \mathrm{~N}$-ammonia body scan of a normal subject. Data from the HEG body scan were used to produce this image. Increasing dot density indicates increasing ${ }^{13} \mathrm{~N}$ activity. When 17 or more levels are required, recycling occurs (in bladder area). The brain, liver, and urinary bladder are easily seen; additional activity is seen in the region of the heart and left kidney. Additional data processing permitted the calculation of organ activities (shown in Table II).

creased to $2.8 \pm 0.6 \%$ in the subjects with severe liver disease $(P<0.01)$ even though renal function was normal (exception, subject No. 21). This may be because of a decrease in the rate of urea synthesis in the liver 
TABLE II

The Distribution of Ammonia Metabolism in Man

\begin{tabular}{|c|c|c|c|c|c|}
\hline Organ & Controls & $\begin{array}{l}\text { Mild liver } \\
\text { disease }\end{array}$ & $\begin{array}{l}\text { Metastatic } \\
\text { cancer }\end{array}$ & $\begin{array}{c}\text { Severe liver } \\
\text { disease }\end{array}$ & Comments \\
\hline Brain & $6.9 \pm 0.5$ & $6.6,6.0,9.4$ & $4.7,7.9$ & $7.7 \pm 0.3$ & $0.05<P<0.10$ \\
\hline Liver* & $7.1 \pm 0.7$ & $9.6,8.0,17.1$ & $24.1, * 17.0^{*}$ & $10.6 \pm 1.5$ & $\begin{array}{l}\text { Uptake depends } \\
\text { on size }\end{array}$ \\
\hline Urine and bladder & $6.4 \pm 1.1$ & $7.2,4.1,10.9$ & $0.0,3.1$ & $2.8 \pm 0.6$ & $P<0.01$ \\
\hline Blood $\ddagger$ & $6.4 \pm 0.3$ & $5.6,-,-$ & $4.9,7.0$ & $6.4 \pm 0.6$ & NS \\
\hline Thigh area & $1.7 \pm 0.1$ & $1.3,1.5,1.3$ & $0.6,0.9$ & $1.2 \pm 0.1$ & $P<0.025$ \\
\hline
\end{tabular}

The percent of the observed ${ }^{13} \mathrm{~N}$ activity contained in each organ at equilibrium was calculated from the data in the body scans. The comparisons are between the normal subjects $(n=5)$ and those with severe liver disease $(n=12)$.

* Includes isotope in tumor.

$\$$ Includes four normal subjects, one with mild liver disease, two with cancer, and seven with severe liver disease.

associated with cirrhosis (20). The fraction of the dose taken up by the liver, excluding the two subjects with metastatic cancer, appeared to be a function of liver size: uptake $(\%)=0.07$ (liver area in $\left.\mathrm{cm}^{2}\right)-1.2, r=+0.85$, $P<0.005$.

The ${ }^{13} \mathrm{~N}$ activity in the brain, liver, blood, and bladder with its contents accounted for $29 \pm 4 \%$ of the total amount of the isotope in the scans. Because animal studies have shown that skeletal muscle traps significant amounts of ammonia (21), an attempt was made to measure muscle uptake in some subjects. The distribution of radioactivity in the thigh, a region that is predominantly muscle, most closely resembled the expected distribution of muscle radioactivity in a twodimensional projection (i.e., uniformly distributed over the thigh, and not concentrated in the center or at the margins as would be expected if the activity were localized in bone or skin, respectively). Accordingly, the ${ }^{13} \mathrm{~N}$ activity was measured in an $8 \times 8-\mathrm{cm}$ area in the middle of the thigh. In the normal subjects, thigh measurements indicated that this area corresponded to about $1 \mathrm{~kg}$ or $\cong 3.3 \%$ of the total muscle mass of a normal subject $(22)$. Because this area was found to contain $1.7 \pm 0.1 \%$ of the scan ${ }^{13} \mathrm{~N}$ activity (Table II), $\cong 50 \%$ of all of the ${ }^{13} \mathrm{~N}$-ammonia must have been trapped by skeletal muscle in the normal subjects. Cachexia probably caused the reduction in uptake observed in this area in the patients with severe liver disease $(1.2 \pm 0.1 \%$ of the scan ${ }^{13} \mathrm{~N}$ activity).

Brain ammonia utilization. Lateral scintigraphs of the head were recorded in 21 studies and included images of 4 normal subjects. Fig. $5 a-d$ shows a schematic drawing of the major organs in the head, a scintigraph of a normal subject, and the scintigraphs of a patient (No. 22) that were studied during mild and severe encephalopathy. The areas with the highest ${ }^{13} \mathrm{~N}$ activity were those that corresponded to the projections of the regions where gray matter content was maximal (Fig. $5 b)$. The four normal subjects were consistent in regard to this distribution of radioactivity. However, the images of patients with liver disease were more variable and often showed a striking redistribution of the activity, as exemplified by the patterns obtained with patient No. 22 (Figs. $5 c$ and $d$ ). The reduction in the ${ }^{13} \mathrm{~N}$-ammonia uptake into the parietal region of this subject was seen in association with an exacerbation of her encephalopathy. Similar, but less marked differences were observed in subjects Nos. 11 and 14 who had chronic, grade 1-2 encephalopathy and were receiving optimum medical treatment.

The rate at which blood-borne ammonia is trapped by the brain can be calculated if the rate of irreversible removal of ${ }^{13} \mathrm{~N}$-ammonia from the blood and the fraction of the total ${ }^{13} \mathrm{~N}$-ammonia dose trapped by the brain are both known (17). This calculation requires two assumptions: (a) The body is a closed system for ${ }^{13} \mathrm{~N}$ metabolism during the time required to complete the study; (b) ${ }^{13} \mathrm{~N}$-Ammonia is irreversibly lost from the vascular compartment and is trapped by the various body organs. The finding that organ radioactivity remained essentially constant after $15 \mathrm{~min}$ (Fig. 3) supports the first assumption; activity measurements of the brain after the administration of ${ }^{13} \mathrm{~N}$-ammonia (Fig. 3; 23) indicate that the ammonia taken up by brain remains essentially irreversibly trapped. The rate of removal of ${ }^{13} \mathrm{~N}$-ammonia from the vascular compartment is the clearance rate (micromoles per minute); this has been measured as described. The fraction of the isotope that was trapped by the brain was determined from the HEG scan data (percent activity per brain). The product of these two variables yields the brain ammonia utilization rate (BAUR) and has the units of micromoles per minute per whole brain. It should be noted that this approach does not require a knowledge of the specific 

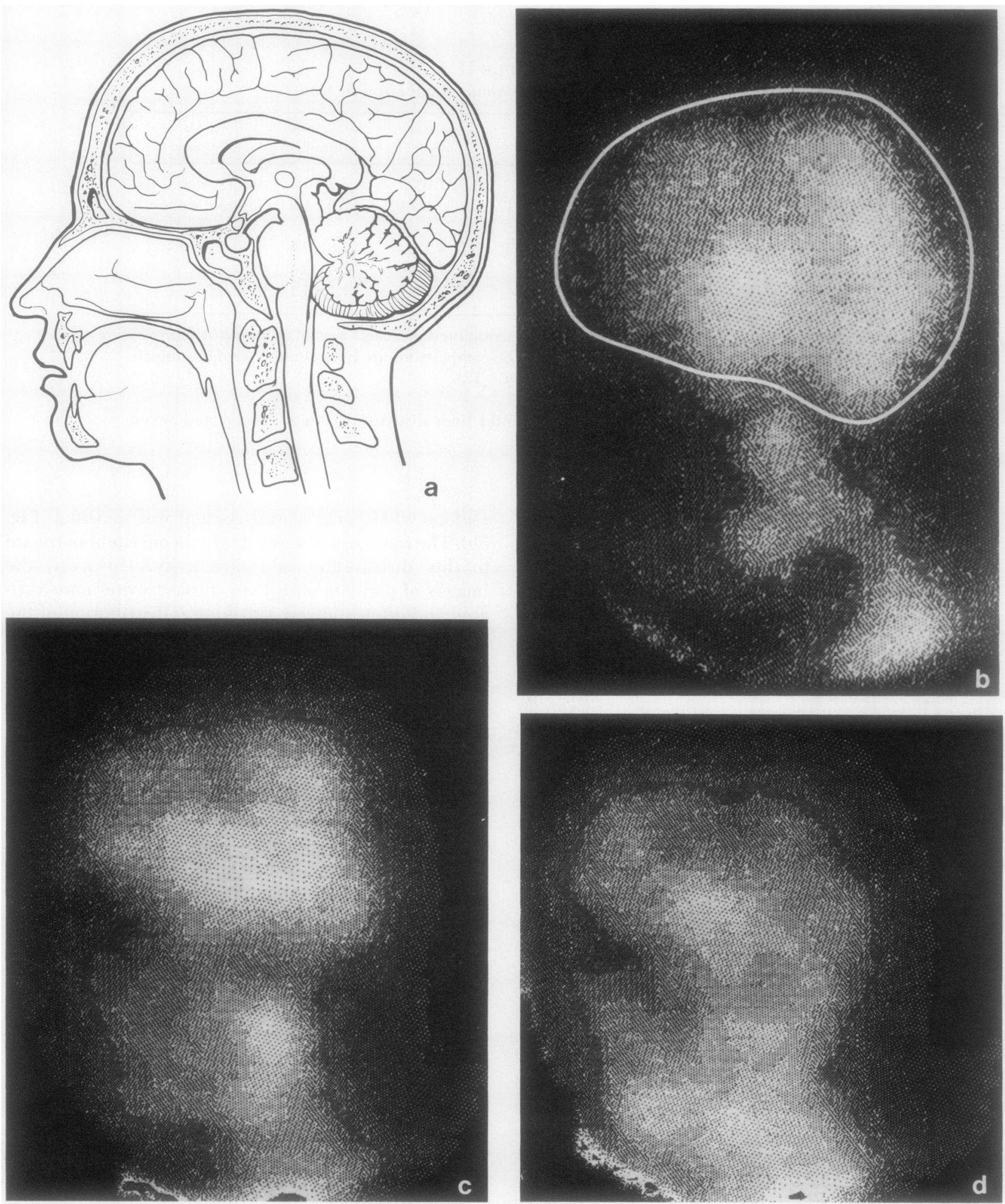

FIGURE $5{ }^{13} \mathrm{~N}$-ammonia uptake by the head. A mid-sagittal drawing of the head is shown in $a$ to facilitate comparisons with scintigraphs. Increasing dot densities indicate increasing levels of ${ }^{13} \mathrm{~N}$ activity. A normal subject is shown in $b$ with a line drawn to indicate the anatomical boundary of the brain. Salivary glands and muscle account for the increase in the activity near the angle of the jaw. The effects of hepatic encephalopathy are seen in $c$ and $d$, the scintigraphs obtained from subject 22 . In the time interval between studies encephalopathy progressed from grade 1 to 3 . The decrease in the parietal ${ }^{13} \mathrm{~N}$-ammonia uptake was seen in other subjects with mild to moderate encephalopathy. 
activity of ammonia in the brain or of the factors that affect the transfer of ammonia across the blood-brain barrier.

The calculated BAUR values for blood-borne ammonia, obtained for the 22 body scans, are plotted in Fig. 6 as a function of each individual's plasma ammonia concentration. The demonstration of a linear relationship between these two variables indicates that the BAUR is a first order process, at least in the range of plasma ammonia concentrations encountered in this study: BAUR $(\mu \mathrm{mol} / \mathrm{min}$ per whole brain $)=0.38$ $\left(\left[\mathrm{NH}_{4}{ }^{+}\right]_{\mathrm{a}}\right)-3.6, r=+0.93, P<0.001$. The findings provide additional support for the hypothesis that ammonia is an important neurotoxin that contributes to the production of hepatic encephalopathy. Subjects without encephalopathy $(n=11)$ had a mean arterial ammonia concentration of $100 \pm 8 \mu \mathrm{M}$ and a BAUR of $32 \pm 3 \mu \mathrm{mol} / \mathrm{min}$ per whole brain. The encephalopathic subjects $(n=11)$ had significantly higher arterial ammonia levels $(149 \pm 18 \mu \mathrm{M} ; P<0.01)$ and higher brain ammonia utilization rates $(53 \pm 7 \mu \mathrm{mol} / \mathrm{min}$ per whole brain; $P<0.01$ ).

Potential sources of error. There are two potential sources of error in the present calculations of organ uptakes in addition to those already discussed. (a) The measured brain activity includes contributions from blood, scalp, and superficial muscle activity as well as brain. (b) The omission of the lower legs from the body scans tends to increase the apparent uptake of ${ }^{13} \mathrm{~N}$ activity by the various organs, because these are expressed as percent of body uptake. On the basis of measurements of cerebral blood volume (24), measurements of the incorporation of ${ }^{13} \mathrm{~N}$-ammonia into muscle (Table II) and into scalp and bone of rats, ${ }^{4}$ and measurements of muscle mass made on leg amputation specimens, ${ }^{5}$ these sources of error have been estimated and are all $<5 \%$. Consequently, they have been ignored.

\section{DISCUSSION}

Brain ammonia metabolism. In humans, direct measurements of the arterial and cerebral venous concentration differences for ammonia have failed to show a consistent pattern for brain ammonia metabolism. Although most data indicate that the brain extracts a small fraction of the ammonia present in arterial blood $(25,26)$, other data show no extraction or ammonia production (27). The failure to demonstrate that ammonia enters the brain has been cited as a weakness in the hypothesis that hyperammonemia produces hepatic encephalopathy (2). The present findings show that arterial ammonia is taken up and used by the brains of all subjects, and that the rate of utilization increases as a linear function of the arterial

\footnotetext{
${ }^{4}$ Freed, B. R. Personal communication.

${ }^{5}$ Lockwood, A. H. Unpublished data.
}

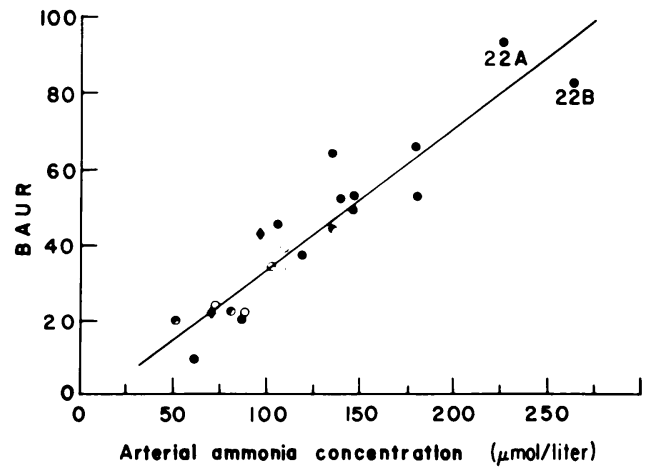

FIGURE 6 BAUR in humans. The BAUR (micromoles per minute per whole brain) was calculated for each subject. The symbols are the same as Fig. 2. The BAUR was a linear function of the arterial ammonia concentration: $\mathrm{BAUR}=0.375$ (ammonia concentration) $-3.6, r=+0.93, P<0.001$.

ammonia concentration. This information, along with the fact that subjects with hepatic encephalopathy had higher arterial ammonia concentrations and BAUR compared to nonencephalopathic subjects, strengthens the hypothesis that hyperammonemia is important in the production of hepatic encephalopathy.

Although the brain contains enzymes that are capable of using and releasing ammonia $(6,28)$, there is little direct information concerning the relative activity of these metabolic pathways. The data of Fazekas et al. (25), obtained by direct measurement of the arterial (a) and cerebral venous ( $v$ ) ammonia concentrations, show that the brains of alert patients extract $11 \pm 2 \%$ of the ammonia in arterial blood, ([a-v]/a). On the assumption that normal adults have a cerebral blood flow of $55 \mathrm{ml} /$ $100 \mathrm{~g}$ per $\min (26)$ and a brain weight of $1,400 \mathrm{~g}$ (men) or $1,260 \mathrm{~g}$ (women) (29), it is possible to calculate the cerebral venous ammonia concentration by equating the BAUR with the product of blood flow and the cerebral arterio-venous concentration difference for ammonia $\left(\right.$ BAUR $=$ cerebral blood flow $\times[a-v]_{\text {ammonia }}$ ). The fraction of the ammonia extracted by the brain can then be calculated. In the five normal subjects, $47 \pm 3 \%$ of the ammonia was extracted, a value similar to that measured in rhesus monkeys (23). The apparent conflict between the chemical data, a measure of the net extraction, and the tracer data, a measure of the forward flux across the blood-barrier, can be explained by assuming that the brain produces and consumes ammonia under normal conditions. If the rate of production is $80 \%$ of the rate of utilization, extractions of 11 and $47 \%$, respectively, would be measured by these two methods.

The rapidity with which ammonia irreversibly enters the brain, combined with the measurements of the BAUR, suggests that ammonia metabolism, like that of glutamate and glutamine $(28,30)$, is compartmented in the brain. If one assumes that ammonia is as free to diffuse out of the brain as it is to diffuse in, persistence of the label in the brain (see Fig. 3) as the blood ${ }^{13} \mathrm{~N}$ - 
ammonia specific activity falls rapidly (90\% in $1 \mathrm{~min}$; see Fig. 1) indicates that the brain has trapped the ammonia. The size of the pool that is labeled by bloodborne ammonia can be estimated from the BAUR data. A hypothetical normal male with an arterial ammonia concentration of $100 \mu \mathrm{M}$ should have $175 \mu \mathrm{mol}$ of ammonia in his brain (based on a $1.4 \mathrm{~kg}$ brain weight [29] and a blood:brain ammonia ratio of 1.00:1.25 calculated from data obtained in rats [31]). Our data predict a BAUR of $33.9 \mu \mathrm{mol} / \mathrm{min}$ per whole brain for such an individual. If the ${ }^{13} \mathrm{~N}$-ammonia that entered the brain equilibrated with the whole brain ammonia pool, the brain ${ }^{13} \mathrm{~N}$ content would be expected to fall during the period of the rapid decrease in the arterial ${ }^{13} \mathrm{~N}$ ammonia specific activity, because only $34 / 175$ or $\cong 1 / 5$ of the ${ }^{13} \mathrm{~N}$-tagged ammonia pool would be metabolically trapped in that 1-min period. Because this was not observed, the maximum size of this compartment must be less than or approximately equal to the amount of ammonia metabolized during the period of the most rapid fall in blood activity, i.e., $\cong 1 \mathrm{~min}$. Thus this compartment should contain $33.9 \mu \mathrm{mol}$ or less of ammonia, or $<20 \%$ of the total brain ammonia pool. This small ammonia pool may be in the astrocytes, because most of the ammonia that enters the brain amidates glutamate to form glutamine $(28,32)$, and glutamine synthetase is an astrocytic enzyme (33).

Phelps et al. (23) have suggested that variations in local capillary density are largely responsible for differences in regional cerebral ammonia uptake. However, most of the ammonia taken up by the brain is rapidly incorporated into the amide nitrogen of glutamine $(28,32)$, suggesting that metabolic factors also influence cerebral ammonia uptake. Because altered brain metabolism is a hallmark of hepatic encephalopathy $(1,2,26,34)$, the regional differences in cerebral ${ }^{13} \mathrm{~N}$-ammonia uptake observed in some encephalopathic subjects (Fig. $5 c$ and $d$ ) are likely to be a result, in part, of metabolic abnormalities. Cerebral ammonia uptake is thus probably controlled by a complex interaction of metabolic and anatomic factors.

Systemic ammonia metabolism. The quantitative data from this study permit the expansion of previous models of human ammonia metabolism (5) by including the amount and rate of ammonia metabolism that proceeds via the systemic vascular pool, and by emphasizing the importance of skeletal muscle in the intermediary metabolism of ammonia. The systemic vascular pool is the central point in this proposed model (Fig. 7). The five normal subjects had a mean arterial ammonia concentration of $98 \pm 7 \mu \mathrm{M}$ and a mean rate of clearance of ammonia from the vascular compartment of $460 \pm 60 \mu \mathrm{mol} / \mathrm{min}$ or $0.66 \pm 0.09 \mathrm{~mol} / \mathrm{d}$. These values do not include the ammonia metabolized by the liver via the hepatic portal vein, and therefore represent a minimum value for the total amount of

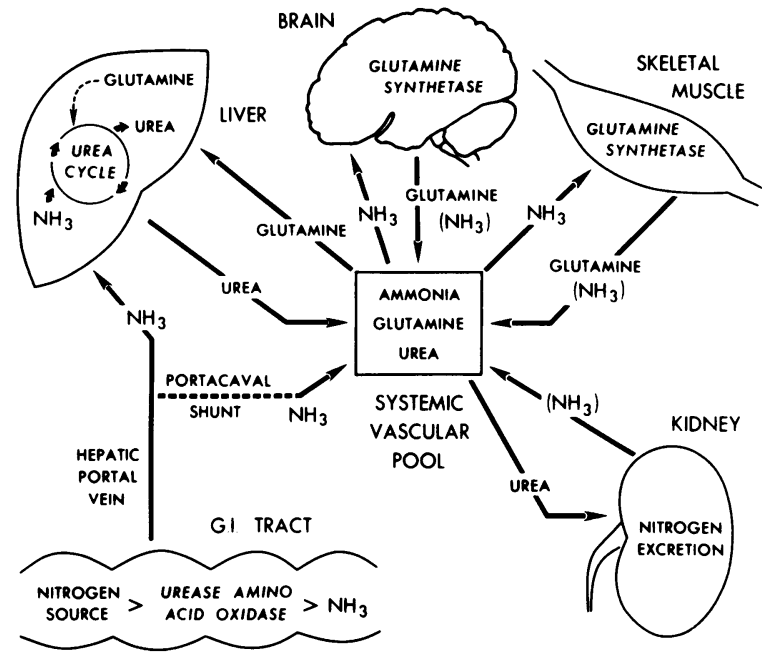

Figure 7 Human ammonia metabolism. Most ammonia is formed in the colon by the action of bacterial urease and amino acid oxidase; the brain, kidney, and skeletal muscle are also sites of ammonia production. Normal subjects detoxify ammonia from the gastro-intestinal (G.I.) tract by conversion to urea. Portacaval shunts direct ammonia into the systemic circulation, causing hyperammonemia and an increase in the BAUR. The rate of ammonia clearance from the blood is a linear function of its arterial concentration; $50 \%$ of this ammonia is taken up by skeletal muscle, the most important organ in ammonia homeostasis in patients with portacaval shunts.

ammonia metabolized by each subject. The five subjects with end-to-side portacaval shunts were all on low protein diets $(0-40 \mathrm{~g} / \mathrm{d})$, had a mean arterial ammonia concentration of $135 \pm 7 \mu \mathrm{mol} / \mathrm{liter}$, and an ammonia clearance rate of $680 \pm 55 \mu \mathrm{mol} / \mathrm{min}$, or 0.98 $\pm 0.08 \mathrm{~mol} / \mathrm{d}$. Because the shunted patients did not have a functioning hepatic portal system, these data more nearly represent the net whole body ammonia metabolic rate. Even with severe dietary protein restrictions, $\cong 1 \mathrm{~mol}$ of ammonia must be eliminated from the body each day.

The importance of skeletal muscle in the maintenance of ammonia homeostasis is due to its large mass, over $40 \%$ of the body weight in normal humans (22). Although the liver is undoubtedly the most important organ in the maintenance of physiological blood ammonia levels in normal humans, in patients with advanced liver disease and portalsystemic shunting, ammonia-laden portal blood bypasses the liver and is diverted into the systemic circulation. Under these circumstances, skeletal muscle may become the most important organ in ammonia homeostasis. The arterio-venous concentration difference for ammonia across normal resting skeletal muscle is close to zero $(35,36)$, indicating that there is no net production or utilization of ammonia. Because there was metabolic trapping of ${ }^{13} \mathrm{~N}$ - 
ammonia by muscle in every subject (Table II), muscle, like brain, must continually use and produce ammonia. In a further parallel with brain, skeletal muscle contains glutamine synthetase (37), and data obtained with rat skeletal muscle in vitro indicate that the concentration of ammonia in the incubation medium is the rate-limiting factor in muscle glutamine production (37). In patients with chronic liver disease and hyperammonemia, the rates of ammonia uptake from the plasma and of glutamine release by skeletal muscle have been found to be increased $(35,36)$.

If ammonia entering the liver via the hepatic artery was the only source of nitrogen for urea synthesis, the five patients with end-to-side portacaval shunts would only be able to synthesize $0.05 \mathrm{~mol}$ of urea per day (calculated from the data of Table II and Fig. 2). Because this rate of urea formation is $<10 \%$ of that predicted in cirrhotic patients with shunts (20), other nitrogenous compounds must be acting as precursors. Glutamine, formed by skeletal muscle, brain, and other organs during periods of hyperammonemia, is a likely candidate in this regard. Gelbard et al. (11) have shown that intravenously injected ${ }^{13} \mathrm{~N}$-glutamine is taken up by the liver in normal dogs. In experiments in which ${ }^{15} \mathrm{~N}$-glutamine was administered intravenously in rats, ${ }^{15} \mathrm{~N}$-urea was recovered from the liver within $10 \mathrm{~min}$ (7). Thus, in humans with hyperammonemia and portal-systemic shunting, skeletal muscle and other organs may detoxify ammonia by converting it to glutamine. Glutamine, in turn, may be carried to the liver and serve as a urea precursor, possibly after deamidation.

Most of the effective treatments for acute or chronic hepatic encephalopathy are directed toward reducing the amount of ammonia that enters the systemic circulation from the gastrointestinal tract $(1,2)$. Our data suggest that the maintenance of a normal skeletal muscle mass may also be important for reducing plasma ammonia. In an unselected series of patients who had emergency portacaval shunts, severe muscle wasting was associated with a worse prognosis for survival than any of the other more usual indicators of severe liver disease, including small liver size, presence of ascites, and reversal of blood flow in the hepatic portal vein (38). Fischer et al. (39) have recently suggested infusing amino acids into patients with hepatic encephalopathy to normalize the balance of neurotransmitters in the brain. Garber et al. (37) have shown that many of the amino acids in the infusion mixture used by Fischer et al. (39), including isoleucine, leucine, lysine, methionine, phenylalanine, valine, and cysteine stimulate glutamine synthesis by skeletal muscle. This may account for the reduction in blood ammonia levels and the therapeutic effect of the amino acid infusion that Fischer et al. (39) reported. Because skeletal muscle metabolizes large amounts of ammonia, reductions in its bulk may contribute to the development of hyperammonemia, particularly in the presence of significant portal-systemic shunting.

\section{ACKNOWLEDGMENTS}

We thank Miss Nancy F. Cruz and Mrs. Nancy G. Cory for their skillful technical assistance and the physicians of the New York Hospital, New York who allowed us to study their patients.

This work was supported, in part, by U. S. Public Health Service grant AM-16739, National Cancer Institute Core grant CA 08748-12, and Energy Research and Development Agency contract EE 775024268 A 000.

\section{REFERENCES}

1. Schenker, S., K. J. Breen, and A. M. Hoyumpa, Jr. 1974. Hepatic encephalopathy: current status. Gastroenterology. 66: $121-151$.

2. Walker, C. O., and S. Schenker. 1970. Pathogenesis of hepatic encephalopathy-with special reference to the role of ammonia. Am. J. Clin. Nutr. 23: 619-633.

3. Menkes, J. G. 1974. Textbook of Child Neurology. Lea \& Febiger, Philadelphia. 12-15, 271-272.

4. Brown, T., G. Hug, L. Lansky, K. Bove, M. Scheve, H. Ryan, H. Brown, W. K. Schubert, J. C. Partin, and J. Lloyd-Still. 1976. Transiently reduced activity of carbamyl phosphate synthetase and ornithine transcarbamylase in liver of children with Reye's syndrome. N. Engl. J. Med. 294: 831-867.

5. McDermott, W. V., Jr. 1957. Metabolism and toxicity of ammonia. N. Engl. J. Med. 257: 1076-1081.

6. Lowenstein, J. M. 1972. Ammonia production in muscle and other tissues: the purine nucleotide cycle. Physiol. Rev. 52: 382-414.

7. Duda, G. G., and P. Handler. 1958. Kinetics of ammonia metabolism in vivo. J. Biol. Chem. 232: 303-314.

8. Stein, T. P., M. J. Leskiw, and H. W. Wallace. 1976. Metabolism of parenterally administered ammonia. J. Surg. Res. 21: 17-20.

9. Lockwood, A. H., J. M. McDonald, A. S. Gelbard, R. E. Reiman, T. E. Duffy, J. S. Laughlin, and F. Plum. 1976. Cerebral ammonia metabolism in liver disease in man. Clin. Res. 34: 433A. (Abstr.)

10. Lockwood, A. H., J. M. McDonald, R. E. Reiman, A. S. Gelbard, J. S. Laughlin, T. E. Duffy, and F. Plum. 1977. The dynamics of ammonia metabolism in man. Gastroenterology. 73: 1232.

11. Gelbard, A. S., L. P. Clarke, J. M. McDonald, W. G. Monahan, R. S. Tilbury, T. Y. T. Kuo, and J. S. Laughlin. 1975. Enzymatic synthesis and organ distribution studies with ${ }^{13} \mathrm{~N}$-labeled L-glutamine and L-glutamic acid. Radiology. 116: 127-132.

12. Folbergrová, J., J. V. Passonneau, O. H. Lowry, and D. W. Schulz. 1969. Glycogen, ammonia and related metabolites in the brain during seizures evoked by methionine sulfoximine. J. Neurochem. 16: 191-203.

13. Monahan, W. G., J. W. Beattie, M. D. Powell, and J. S. Laughlin. 1973. Total organ kinetic imaging monitor: system design and applications. In Medical Isotope Scintigraphy. The International Atomic Energy Agency, Vienna.

14. Van Slyke, D. D., R. A. Phillips, V. P. Dole, P. B. Hamilton, R. M. Archibald, and J. Plazin. 1950. Calculation of hemoglobin from blood specific gravities. J. Biol. Chem. 183: 349-360. 
15. Clarke, L. P., J. S. Laughlin, and K. Mayer. 1972. Quantitative organ uptake measurement. Radiology. 102: 375382.

16. Clarke, L. P., E. Z. Maugham; J. S. Laughlin, W. H. Knapper, and K. Mayer. 1976. Calibration methods for measuring splenic sequestration by external scanning. Med. Phys. 3: 324-327.

17. Shipley, R. A., and R. E. Clark. 1972. Tracer methods for in vivo kinetics: theory and application. Academic Press, Inc., New York. 93-95.

18. Jones, D. E. A., and H. C. Raine. 1949. Letter to the editor. Br. J. Radiol. 22: 549-550.

19. Kuhl, D. E., R. Q. Edwards, A. R. Ricci, R. J. Yacob, T. J. Mich, and A. Alavi. 1976. The Mark IV system for radionuclide computed tomography of the brain. Radiology. 121: 405-413.

20. Rudman, D., T. J. DiFulco, J. T. Galambos, R. B. Smith, III, A. A. Salam, and W. D. Warren. 1973. Maximal rates of excretion and synthesis of urea in normal and cirrhotic subjects. J. Clin. Invest. 52: 2241-2249.

21. Lockwood, A. H., R. D. Finn, and J. A. Campbell. 1978. Methionine sulfoximine enhances rat brain ${ }^{13} \mathrm{~N}$-ammonia detoxification. Neurology. 28: 374. (Abstr.)

22. Morgan, K. Z., W. Binks, A. M. Brues, A. J. Cipriani, W. H. Langham, L. D. Marinelli, W. G. Marley, G. J. Neary, and E. E. Pochin. 1955. Report of international subcommittee II on permissible dose for internal radiation. Br. J. Radiol. Suppl. 6: 25.

23. Phelps, M. E., E. J. Hoffman, R. E. Coleman, M. J. Welch, M. E. Raichle, E. S. Weiss, B. E. Sobel, and M. M. Ter-Pogossian. 1976. Tomographic images of blood pool and perfusion in brain and heart. J. Nucl. Med. 17: 603-612.

24. Grubb, R. L., Jr., M. E. Raichle, J. O. Eichling, and M. M. Ter-Pogossian. 1974. The effects of changes in $\mathrm{PaCO}_{2}$ on cerebral blood volume, blood flow, and mean vascular transit time. Stroke. 5: 630-639.

25. Fazekas, J. F., H. E. Ticktin, W. R. Ehrmantraut, and R. W. Alman. 1956. Cerebral metabolism in hepatic insufficiency. Amer. J. Med. 21: 843-849.

26. Posner, J. B., and F. Plum. 1960. The toxic effects of carbon dioxide and acetazolamide in hepatic encephalopathy. $J$. Clin. Invest. 39: 1246-1258.

27. Webster, L. T., and G. J. Gabuzda. 1958. Ammonium uptake by the extremities and brain in hepatic coma. J. Clin. Invest. 37: 414-424.
28. Berl, S., G. Takagaki, D. D. Clarke, and H. Waelsch. 1962. Metabolic compartments in vivo: ammonia and glutamic acid metabolism in brain and liver. J. Biol. Chem. 237: 2562-2569.

29. Korenchevsky, V. 1961. Physiological and Pathological Aging. Hafner Publishing Co., Inc., New York. 42.

30. Berl, S., and Clarke, D. D. 1969. Compartmentation of amino acid metabolism. In Handbook of Neurochemistry. Plenum Press, New York. 2: 447-472.

31. Hindfelt, B., F. Plum, and T. E. Duffy. 1977. Effect of acute ammonia intoxication on cerebral metabolism in rats with portacaval shunts. J. Clin. Invest. 59: 386-396.

32. Cooper, A. J. L., J. M. McDonald, A. S. Gelbard, and T. E. Duffy. 1978. Metabolic fate of ${ }^{13} \mathrm{~N}$-labeled ammonia in rat brain. Transactions American Society for Neurochemistry. 9: 187.

33. Martinez-Hernández, A., K. P. Bell, and M. D. Norenberg. 1977. Glutamine synthetase: glial localization in brain. Science (Wash. D. C.). 195: 1356-1358.

34. Gjedde, A., A. H. Lockwood, T. E. Duffy, and F. Plum. 1978. Cerebral blood flow and metabolism in chronically hyperammonemic rats: effect of an acute ammonia challenge. Ann. Neurol. 3: 325-330.

35. Bessman, S. P., and E. J. Bradley. 1955. Uptake of ammonia by muscle: its implications in ammoniagenic coma. N. Engl. J. Med. 253: 1143-1147.

36. Ganda, O. P., and N. B. Ruderman. 1976. Muscle nitrogen metabolism in chronic hepatic insufficiency. Metab. Clin. Exp. 25: 427-435.

37. Garber, A. J., I. E. Karl, and D. M. Kipnis. 1976. Alanine and glutamine synthesis and release from skeletal muscle II. The precursor role of amino acids in alanine and glutamine synthesis. J. Biol. Chem. 251: 836-843.

38. Orloff, M. J., A. C. Charters, III, J. G. Chandler, J. K. Condon, D. E. Grambort, T. R. Mondafferi, S. E. Levin, N. B. Brown, S. G. Sviokla, and D. G. Knox. 1975. Portacaval shunt as emergency procedure in unselected patients with alcoholic cirrhosis. Surg. Gynecol. Obstet. 141: $59-68$.

39. Fischer, J. E., H. M. Rosen, A. M. Ebeid, J. H. James, J. M. Keane, and P. B. Soeters. 1976. The effect of normalization of plasma amino acids on hepatic encephalopathy in man. Surgery (St. Louis). 80: 77-91. 